\title{
Effects of fucoidan on insulin stimulation and pancreatic protection via the cAMP signaling pathway in vivo and in vitro
}

\author{
XIAOMING JIANG ${ }^{1}$, JINFENG YU ${ }^{2}$, ZHI MA $^{3}$, HONG ZHANG $^{1}$ and FENGJIE XIE ${ }^{1}$ \\ Departments of ${ }^{1}$ Critical Care Medicine, ${ }^{2}$ Pediatric Medicine and ${ }^{3}$ Pediatric Surgery Medicine, \\ Hongqi Hospital of Mudanjiang Medical University, Mudanjiang, Heilongjiang 157011, P.R. China
}

Received September 22, 2014; Accepted May 28, 2015

DOI: $10.3892 / \mathrm{mmr} .2015 .3989$

\begin{abstract}
Diabetes is a global disease, in which pancreatic dysfunction is an important pathological process. In previous years, interest in the biological activities of seaweed has increased. Fucoidan is an extract of the seaweed Fucus vesiculosus, which has been widely investigated. The present study aimed to determine the effects of fucoidan on insulin stimulation and pancreatic protection in vivo and in vitro. Goto-Kakizaki (GK) rats were provided with free access to standard food, with or without fucoidan, for 13 weeks, following which the body weights, and blood glucose and serum insulin levels of the rats were measured. Wistar rats were used as a control. In addition, the RIN-5F rat insulin-secreting cell line was treated with fucoidan in high glucose conditions, following which the dose-dependent and time-dependent effects of fucoidan were determined, and the concentration of insulin was measured. Glybenclamide was used as a positive control. In vivo, the body weight and serum insulin levels decreased, whereas blood glucose levels increased significantly in the GK rats, compared with the Wistar control rats. Although, fucoidan did not improve changes in body weight, the increased blood glucose levels were reduced and the decreased serum insulin levels were increased in the GK rats following oral administration of fucoidan. In vitro, fucoidan did not exhibit significant cytotoxicity towards the RIN-5F cells, and the insulin secretion increased significantly in a dose- and time-dependent manner. Treatment with amylin, an islet amyloid polypeptide and glybenclamide inhibitor, did not inhibit the stimulatory activity of fucoidan. The results of the present study also demonstrated that the concentration of cyclic adenosine monophosphate (cAMP) was significantly increased in the fucoidan-treated RIN-5F cells, and this increase was dose- and time-dependent. In addition, treatment with a phosphodiesterase inhibitor, which decreases the degradation of cAMP, significantly
\end{abstract}

Correspondence to: Dr Fengjie Xie, Department of Critical Care Medicine, Hongqi Hospital of Mudanjiang Medical University, 5 Tongxiang Road, Aimin, Mudanjiang, Heilongjiang 157011, P.R. China E-mail: mdjxfj1971@sina.com

Key words: fucoidan, Goto-Kakizaki rats, RIN-5F cells, insulin, cyclic adenosine monophosphate increased fucoidan-induced insulin secretion, whereas treatment with an adenylyl cyclase inhibitor, which decreases the generation of cAMP, significantly decreased fucoidan-induced insulin secretion. In conclusion, these data indicated that fucoidan may stimulate insulin secretion and provide pancreatic protection via the cAMP signaling pathway, in vivo and in vitro.

\section{Introduction}

Diabetes mellitus is a global disease (1), which affects $>200,000,000$ individuals. The majority of patients with diabetes have non-insulin-dependent diabetes mellitus (NIDDM; type 2 diabetes), and the number of patients with this disease is expected to double by 2030 (2). The insulin stimulatory activities of sulfonylureas (SUs), which are used to treat patients with NIDDM, have been reported to decrease with time due to the gradual destruction of pancreatic $\beta$ cells. In addition, SUs are prescribed with several restrictions due to their side-effects, including hypoglycemia (3). Therefore, the production of an alternative antidiabetic treatment, which exhibits low toxicity following extended use is required.

Interest in the biological activities of compounds from marine organisms has increased over previous years (4). Compounds derived from various marine organisms have been investigated $(5,6)$, a number of which have resulted in the production of commercially available drugs (3). Fucoidan (Fig. 1) is an extract of the seaweed, Fucus vesiculosus, which has been widely investigated (7). Due to its anti-oxidative, anticancer, and anti-inflammatory activities, it has been suggested to be important in cancer and inflammation (8). In addition, fucoidan has been reported to be associated with insulin resistance (9); however, the effects of fucoidan on insulin stimulation and pancreatic protection in spontaneous diabetes have not been investigated. Insulin is a key regulator of body glucose levels (10); therefore, the present study aimed to determine whether fucoidan can stimulate insulin secretion and protect pancreatic function.

Under physiological conditions, the insulin secretory response to glucose is augmented by several factors, which act through various mechanisms (11). Cyclic adenosine monophosphate (cAMP) is an important amplifier of insulin release (12). It is known that cAMP directly inhibits adenosine triphosphate (ATP)-sensitive $\mathrm{K}^{+}$channels, and promotes depolarization of the plasma membrane. In addition, cAMP increases cytosolic $\mathrm{Ca}^{2+}$ levels via the opening of L-type voltage-sensitive $\mathrm{Ca}^{2+}$ 
channels in the plasma membrane and promoting $\mathrm{Ca}^{2+}$-induced $\mathrm{Ca}^{2+}$ release from intracellular stores (13).

To the best of our knowledge, the present study is the first to determine the effects of fucoidan on insulin stimulation and pancreatic protection These data indicate that fucoidan stimulates insulin secretion and provides pancreatic protection via the cAMP signaling pathway in vitro and in vivo. Furthermore, these results indicate that fucoidan may prevent or reduce the development of spontaneous diabetes and provide a potential novel therapeutic strategy for the treatment of diabetes.

\section{Materials and methods}

Animals. The present study was perforned at the Animal Experimental Center of Mudanjiang Medical University (Mudanjiang, China). Animal care and experiments were performed in accordance with the Animal Experiment Guidelines of Mudanjiang Medical University, and ethical approval was obtained from Mudanjiang Medical University. Male Goto-Kakizaki (GK) and Wistar rats (aged, 6 weeks) were obtained from CLEA Japan, Inc. (Tokyo, Japan). The rats were divided into three groups (Wistar, GK and GK/fucoidan group) and each group contained 8 rats The rats were housed in a controlled environment, with a temperature of $24 \pm 1^{\circ} \mathrm{C}$, and a $12 \mathrm{~h} \mathrm{light} / 12 \mathrm{~h}$ dark cycle, with light turned on at $7 \mathrm{a} . \mathrm{m}$. The rats were provided with access to standard rat food and water ad libitum, with or without fucoidan at the recommended concentration of $75 \mathrm{mg} / \mathrm{kg}$ body weight (14) for 13 weeks, beginning at 6 weeks of age.

Measurement of blood glucose levels. At 6-weeks-old, the GK rats were provided with access to standard rat food and water, with or without $75 \mathrm{mg} / \mathrm{kg}$ body weight fucoidan (Sigma-Aldrich, Shanghai, China) for 13 weeks. The body weight of each rat was measured twice per week. Blood samples $(20 \mu \mathrm{l})$ were obtained from the tail vein every week. The blood glucose levels were measured using a hexokinase method (15), with a rat blood glucose kit (Wako Pure Chemical Industries, Ltd., Tokyo, Japan).

Histopathological studies. For histopathological analysis, the rats were sacrificed using $0.3 \mathrm{ml} / 100 \mathrm{~g}$ body weight chloral hydrate (Sigma-Aldrich), and the pancreata from GK and Wistar rats were fixed in $10 \%$ neutral buffered formalin and subsequently embedded in paraffin. Sections $(4 \mu \mathrm{m})$ of paraffin-embedded tissues were stained with hematoxylin and eosin (HE; Sigma-Aldrich) solution, in order to detect histopathological features, as described previously (16). Briefly, the pancreata sections were placed in distilled water, stained with alum hematoxylin, rinsed under running tap water, differentiated with $0.3 \%$ acid alcohol, rinsed in running tap water again, and then rinse in Scott's tap water substitute (Sigma-Aldrich) before rinsing in tap water again. The pancreata were then stained with eosin for 2 mins. An image of the cross-section yielding the maximum diameter of the glomerulus was captured and converted into a digital image by an examiner in a blinded-manner, using a light microscope equipped with a camera (Olympus BX-50; Olympus Corporation, Tokyo, Japan).

RIN-5F cell culture. The RIN-5F rat insulin-secreting cell line, derived from rat pancreatic $\beta$ cells, was purchased from American
Type Culture Collection (Manassas, VA, USA). The RIN-5F cells were cultured in RPMI 1640 medium (Sigma-Aldrich) supplemented with penicillin $(100 \mathrm{U} / \mathrm{ml})$, streptomycin $(100 \mu \mathrm{g} / \mathrm{ml})$ and $10 \%$ fetal bovine serum (FBS; Sigma-Aldrich) at $37^{\circ} \mathrm{C}$, in an atmosphere containing $5 \% \mathrm{CO}_{2}$. Fresh conditioned medium was added every 3 days, and the subcultures were digested every 7-8 days using $0.25 \%$ trypsin (Sigma-Aldrich).

Cytotoxicity analysis. The CellTiter $96{ }^{\circledR}$ AQueous One Solution Cell Proliferation Assay (Promega Corporation, Madison, WI, USA), which has previously been reported as an effective cytoxicity assay (17), was used in the present study to determine the cytotoxicity of fucoidan. The RIN-5F cells were seeded into 96-well plates at a density of $2 \times 10^{4}$ cells/well in conditioned RPMI 1640 medium and incubated at $37^{\circ} \mathrm{C}$ in an atmosphere of $5 \% \mathrm{CO}_{2}$ for $48 \mathrm{~h}$. The cells were then treated with various concentrations of fucoidan $\left(0,10,1 \times 10^{2}, 1 \times 10^{3}, 1 \times 10^{4}\right.$ and $\left.1 \times 10^{5} \mu \mathrm{g} / \mathrm{ml}\right)$ for $24 \mathrm{~h}$ at $37^{\circ} \mathrm{C}$, following which $20 \mu \mathrm{l}$ CellTiter $96^{\circledR}$ AQueous One Solution Cell Proliferation Assay solution was added to each well and the cells were incubated for a further $1 \mathrm{~h}$. The absorbance was measured at $490 \mathrm{~nm}$ using an MTP-800 microplate reader (Corona Electric Co., Ltd., Ibaraki, Japan).

Insulin secretion assay. In vivo, the GK rats at 6 weeks of age were provided with access to standard rat food and water, with or without fucoidan ( $75 \mathrm{mg} / \mathrm{kg}$ body weight), for 13 weeks. Blood samples were obtained from the tail vein every week, in order to perform an insulin secretion assay. In vitro, the RIN-5F cells were seeded into 24 -well plates at a density of $2 \times 10^{5}$ cells/well in RPMI 1640 medium, supplemented with penicillin, streptomycin and $10 \% \mathrm{FBS}$, and incubated at $37^{\circ} \mathrm{C}$ in an atmosphere of $5 \% \mathrm{CO}_{2}$ for $24 \mathrm{~h}$. The cells were then treated with various doses of fucoidan $\left(0,10,1 \times 10^{2}, 1 \times 10^{3}\right.$, $1 \times 10^{4}$ and $1 \times 10^{5} \mu \mathrm{g} / \mathrm{ml}$ ) for $3 \mathrm{~h}$; and with $1 \times 10^{4} \mu \mathrm{g} / \mathrm{ml}$ fucoidan for various durations $(3,6,12,24$ and $48 \mathrm{~h})$, in a $20 \mathrm{mg} / \mathrm{ml}$ high glucose condition. Aliquots of the media were removed from each of the wells and centrifuged $\left(1,175 \mathrm{x} \mathrm{g}\right.$, for $5 \mathrm{~min}$ at $4^{\circ} \mathrm{C}$ ). to remove the cells. The concentration of insulin in the supernatants was determined using an enzyme immunoassay (EIA) kit (Cayman Chemical, Ann Arbor, MI, USA). The absorbance was measured at $490 \mathrm{~nm}$ using an MTP-800 microplate reader (Corona Electric Co., Ltd., Tokyo, Japan).

Treatment with glybenclamide. The RIN-5F cells were seeded in 24-well plates at a density of $2 \times 10^{5}$ cells/well in RPMI-1640 medium supplemented with penicillin, streptomycin and $10 \%$ $\mathrm{FBS}$ at $37^{\circ} \mathrm{C}$ in an atmosphere containing $5 \% \mathrm{CO}_{2}$. After $24 \mathrm{~h}$, the cells were treated with $1 \times 10^{4} \mu \mathrm{g} / \mathrm{ml}$ fucoidan and $1 \times 10^{2} \mu \mathrm{M}$ glybenclamide (Sigma Aldrich) in a $20 \mathrm{mg} / \mathrm{ml}$ high glucose condition. The concentration of insulin in the supernatants was determined using the EIA kit and the absorbance was measured by the MTP 800 microplate reader.

Treatment with amylin. The RIN-5F cells were seeded in 24-well plates at a density of $2 \times 10^{5}$ cells/well in RPMI-1640 medium supplemented with penicillin, streptomycin and $10 \%$ FBS at $37^{\circ} \mathrm{C}$ in an atmosphere containing $5 \% \mathrm{CO}_{2}$. After $24 \mathrm{~h}$ incubation, $200 \mu \mathrm{M}$ amylin (Sigma Aldrich) with either $1 \times 10^{4} \mu \mathrm{g} / \mathrm{ml}$ fucoidan or $1 \times 10^{2} \mu \mathrm{M}$ glybenclamide was added to the wells for $3 \mathrm{~h}$ in a $20 \mathrm{mg} / \mathrm{ml}$ high glucose condition. 
A

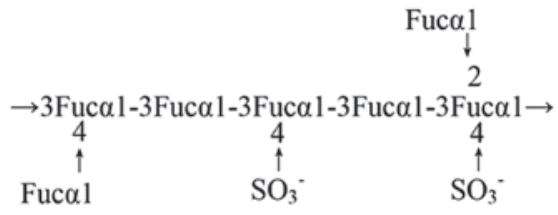

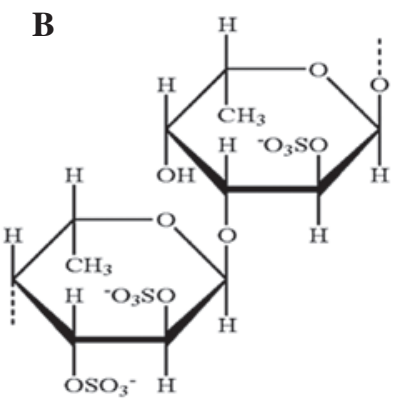

Figure 1. (A) Molecular formula and (B) chemical structure of fucoidan.

Measurement of intracellular cAMP content. The RIN-5F cells were seeded in 24-well plates at a density of $2 \times 10^{5}$ cells/well in RPMI-1640 medium were treated with $1 \times 10^{4} \mu \mathrm{g} / \mathrm{ml}$ fucoidan, $2 \times 10^{5} \mathrm{M}$ phosphodiesterase inhibitor [4-(3-butoxy-4-methoxybenzyl)-2-imidazolidinone; Sigma Aldrich], $2 \times 10^{5} \mathrm{M}$ phosphodiesterase inhibitor $+1 \times 10^{4} \mu \mathrm{g} / \mathrm{ml}$ fucoidan, 5x10 $10^{5}$ MDL 12330A hydrochloride (Sigma Aldrich) or $5 \times 10^{5} \mathrm{M}$ MDL 12330A hydrochloride $+1 \times 10^{4} \mu \mathrm{g} / \mathrm{ml}$ fucoidan, in a $20 \mathrm{mg} / \mathrm{ml}$ high glucose condition. Intracellular cAMP content was measured using an enzyme linked competitive immunoassay kit, containing a cAMP-acetylcholinesterase conjugate and an anti-cAMP rabbit antibody (Cyclic AMP EIA kit; Cayman Chemical), according to the manufacturer's instructions. Briefly, the RIN-5F cells were extracted in $0.05 \mathrm{M} \mathrm{HCl}$ for $20 \mathrm{~min}$ at $22^{\circ} \mathrm{C}$. Following centrifugation at $1,000 \mathrm{x}$ g for $10 \mathrm{~min}$ at $22^{\circ} \mathrm{C}$, the supernatant was used to measure the cAMP content. The quantity of cAMP-acetylcholinesterase-anti-cyclic AMP antibody complex was measured with an enzyme assay using acetylcholine and 5,5-dithio-bis (2-nitrobenzoic acid), termed Ellman's reagent, contained within the Cyclic AMP EIA kit, as previously described (18). The concentration of the final reaction product, 5-thio-2-nitrobenzoic acid, was measured at an absorbance of $420 \mathrm{~nm}$ using an MTP-800 Microplate Reader (Corona Electric, Tokyo, Japan) and was converted to cAMP concentration using the standard curve obtained with authentic cAMP solution in the kit.

Statistical analysis. The data are expressed as the mean \pm standard deviation. Each experiment was repeated at least three times. Student's t-test was used to analyze the data and $\mathrm{P}<0.05$ was considered to indicate a statistically significant difference.

\section{Results}

Fucoidan reduces high blood glucose levels in GK rats. At 6 weeks-old, the GK rats were provided with access to standard rat food and water, with or without fucoidan $(75 \mathrm{mg} / \mathrm{kg}$ body weight), for 13 weeks. Blood samples were obtained from the tail vein every week. Body weight was significantly decreased in the GK rats, compared with the control Wistar rats (Fig. 2A and $\mathrm{B} ; \mathrm{P}<0.01)$. Fucoidan had no effect on body weight; however, the increased levels of blood glucose levels in the GK rats were significantly reduced following oral administration of fucoidan (Fig. 2C and D; P<0.01).

Fucoidan recovers serum insulin levels in GK rats. The GK rats were provided with access to standard rat food and water, with or without fucoidan ( $75 \mathrm{mg} / \mathrm{kg}$ body weight), for 13 weeks from 6 weeks of age. Blood samples were obtained from the tail vein every week. The serum insulin levels were significantly decreased in the GK rats, compared with the control Wistar rats (Fig. 2E and F; P<0.01). The decreased levels of serum insulin observed were significantly recovered in the GK rats following oral administration of fucoidan $(\mathrm{P}<0.01)$.

Fucoidan reduces histopathological pancreatic changes in $G K$ rats. The pancreata from the GK and Wistar rats were fixed in $10 \%$ neutral buffered formalin and subsequently embedded in paraffin. Sections $(4-\mu \mathrm{m})$ of the paraffin-embedded tissues were stained with HE solution, in order to detect histopathological features. Islet atrophy, fibrosis of pancreatic ducts and blood vessels, and macrophages containing brown coarsely granular material were observed in the pancreata of the GK rats, compared with the control Wistar rats (Fig. 3B). Treatment with fucoidan markedly reduced these observed histopathological changes in the pancreata of the GK rats (Fig. 3C).

Fucoidan exhibits no obvious cytotoxicity towards RIN-5F cells. The RIN-5F cells were seeded into 96-well plates at a density of $2 \times 10^{4}$ cells/well in conditioned RPMI 1640 medium at $37^{\circ} \mathrm{C}$ in an atmosphere containing $5 \% \mathrm{CO}_{2}$ for $48 \mathrm{~h}$. The RIN-5F cells were treated with various concentrations of fucoidan $(0,10$, $1 \times 10^{2}, 1 \times 10^{3}, 1 \times 10^{4}, 1 \times 10^{5} \mu \mathrm{g} / \mathrm{ml}$ ) for $24 \mathrm{~h}$, following which $20 \mu \mathrm{l}$ CellTiter $96{ }^{\circledR}$ AQueous One Solution Cell Proliferation Assay solution was added to each well and incubated for a further $1 \mathrm{~h}$. The results of this assay revealed that fucoidan did not exhibit obvious cytotoxicity on RIN-5F cells (Fig. 4A).

Treatment with fucoidan increases the insulin secretion of RIN-5F cells in a dose-and time-dependent manner. RIN-5F cells were seeded in $24-w e l l$ plates at a density of $2 \times 10^{5}$ cells/well in RPMI 1640 supplemented with penicillin, streptomycin and $10 \% \mathrm{FBS}$ at $37^{\circ} \mathrm{C}$ in an atmosphere containing $5 \% \mathrm{CO}_{2}$ for $24 \mathrm{~h}$. The cells were then treated with various doses of fucoidan $(0$, $10,1 \times 10^{2}, 1 \times 10^{3}, 1 \times 10^{4}$ and $1 \times 10^{5} \mu \mathrm{g} / \mathrm{ml}$ ) for $3 \mathrm{~h}$ (Fig. $4 \mathrm{~B}$ ); and with $1 \times 10^{4} \mu \mathrm{g} / \mathrm{ml}$ fucoidan for 3, 6, 12, 24 and $48 \mathrm{~h}$ (Fig. 4C) in a $20 \mathrm{mg} / \mathrm{ml}$ high glucose condition. The results revealed that fucoidan increased insulin secretion in the RIN-5F cells in a dose- and time-dependent manner $(\mathrm{P}<0.01)$.

Stimulatory activities of fucoidan with glybenclamide. The RIN-5F cells were seeded in 24-well plates at a density of $2 \times 10^{5}$ cells/well in RPMI 1640 medium supplemented with penicillin, streptomycin and $10 \% \mathrm{FBS}$ at $37^{\circ} \mathrm{C}$ in an atmosphere 

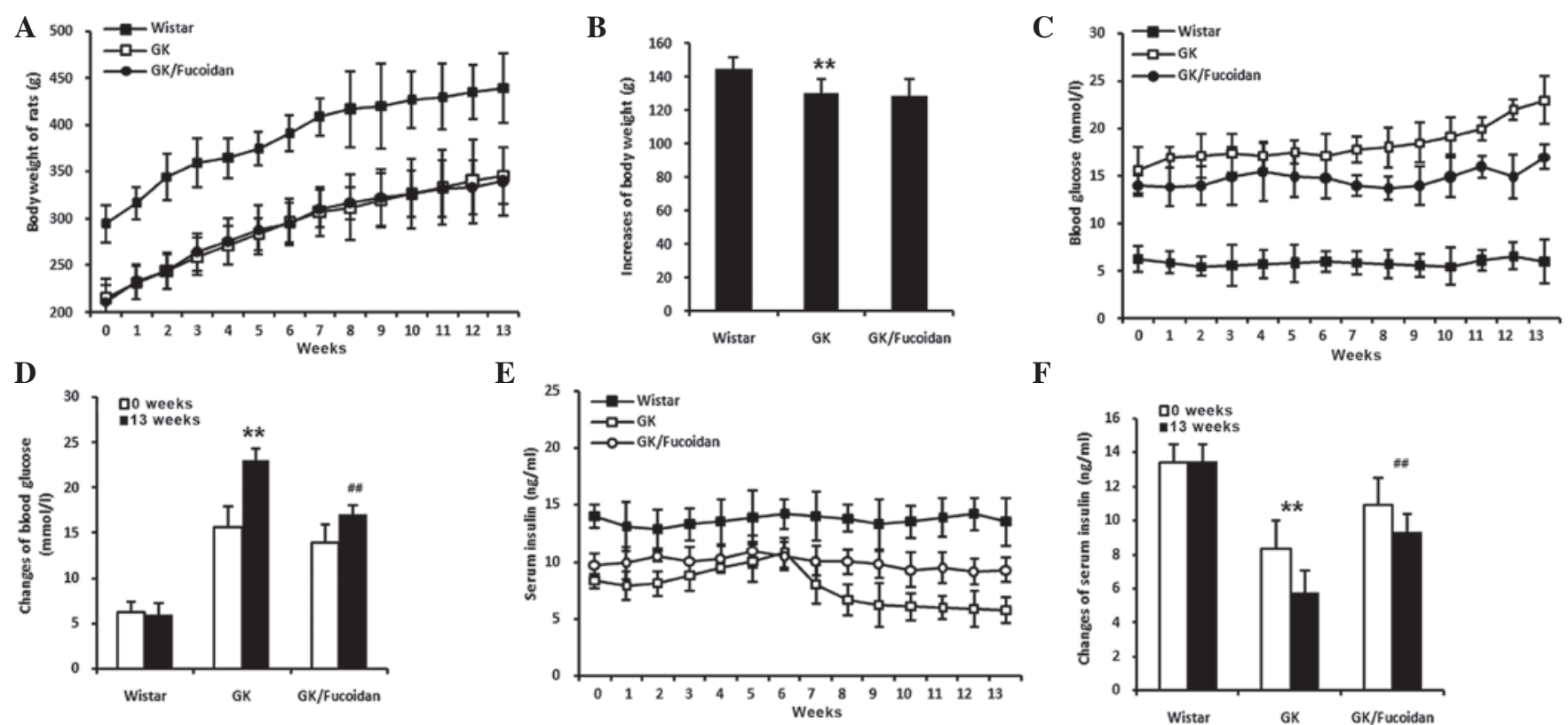

$\mathbf{F}$

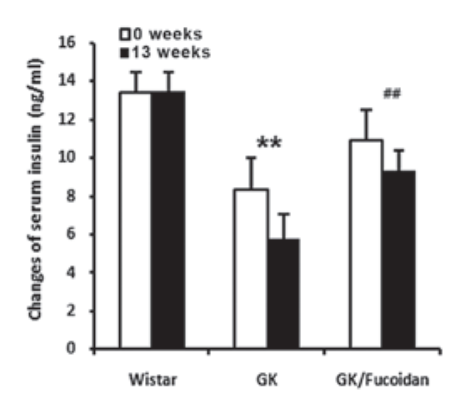

Figure 2. Effects of fucoidan on GK rats. At 6 weeks-old, the GK rats were provided with access to standard rat food and water, with or without fucoidan ( $75 \mathrm{mg} / \mathrm{kg}$ body weight), for 13 weeks. Blood samples were obtained from the tail vein every week. (A) Body weight was significantly decreased in the GK rats, compared with the control Wistar rats; however, fucoidan did not have an affect body weight. (B) Quantification of the increases in body weight after 13 weeks. (C) Blood glucose levels were significantly increased in the GK rats, compared with the control Wistar rats. The blood glucose levels were significantly reduced in the GK rats treated with fucoidan. (D) Quantification of the changes in blood glucose levels between 0 and 13 weeks. (E) Serum insulin levels were significantly decreased in the GK rats, compared with the control Wistar rats. The decreased serum insulin levels were significantly recovered in the GK rats treated with fucoidan. (F) Quantification of the changes in serum insulin levels between 0 and 13 weeks. Data are expressed as the mean \pm standard deviation $(\mathrm{n}=8) .{ }^{* *} \mathrm{P}<0.01$, GK rats, vs. Wistar rats; ${ }^{\# \#} \mathrm{P}<0.01$, GK rats treated with fucoidan, vs. GK rats. GK, Goto-Kakizaki.

A

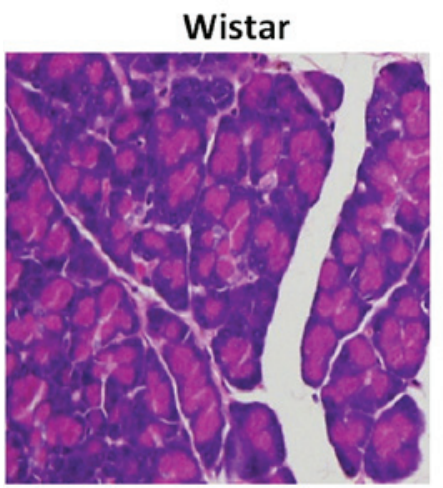

B

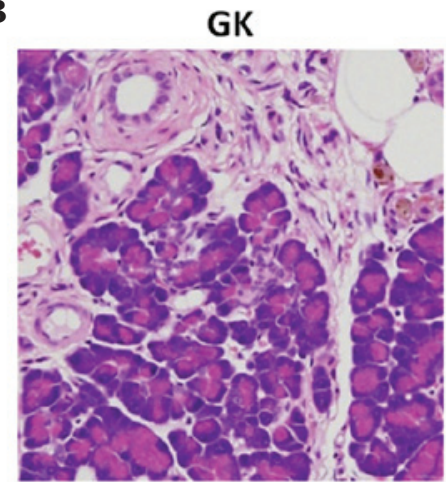

C

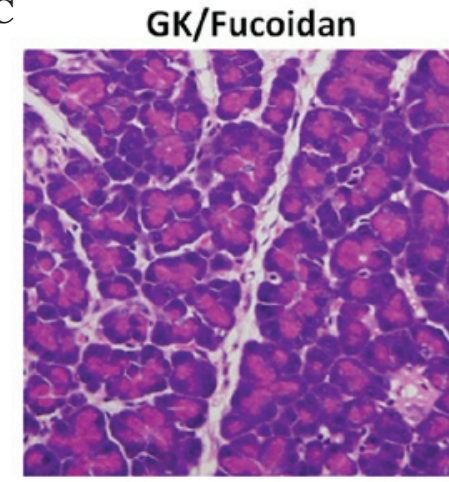

Figure 3. Fucoidan reduces the histopathological pancreatic changes in GK rats. At 6 weeks-old, the GK rats were provided with access to standard rat food and water, with or without fucoidan ( $75 \mathrm{mg} / \mathrm{kg}$ body weight), for 13 weeks. The pancreatic tissues from the GK and Wistar rats were then collected and stained with hematoxylin and eosin, to detect histopathological features. (A) Histopathological features of the pancreatic tissues of the Wistar rats. (B) Islet atrophy, fibrosis of pancreatic ducts and blood vessels, and macrophages containing brown coarsely granular material were observed in the pancreatic tissues of the GK rats. (C) Fucoidan significantly reduced the histopathological changes in the pancreatic tissues of the GK rats (magnification, 400x). GK, Goto-Kakizaki.

containing $5 \% \mathrm{CO}_{2}$. After $24 \mathrm{~h}$, the cells were treated with $1 \times 10^{4} \mu \mathrm{g} / \mathrm{ml}$ fucoidan and $1 \times 10^{2} \mu \mathrm{M}$ glybenclamide, either alone or in combination, in a $20 \mathrm{mg} / \mathrm{ml}$ high glucose condition for $3 \mathrm{~h}$. The results of the treatment suggested an additive effect of fucoidan and glybenclamide (Fig. 5A). Furthermore, the results indicate that the stimulatory effects of fucoidan and glybenclamide arise as a result of different mechanisms

Lack of inhibitory effect of amylin on fucoidan. The RIN-5F cells were seeded in 24-well plates at a density of $2 \times 10^{5}$ cells/well in RPMI 1640 medium supplemented with penicillin, streptomycin and $10 \% \mathrm{FBS}$ at $37^{\circ} \mathrm{C}$ in an atmosphere containing $5 \% \mathrm{CO}_{2}$. After $24 \mathrm{~h}$ incubation, $200 \mu \mathrm{M}$ amylin with either $1 \times 10^{4} \mu \mathrm{g} / \mathrm{ml}$ fucoidan or $1 \times 10^{2} \mu \mathrm{M}$ glybenclamide was added to the wells for $3 \mathrm{~h}$ in a $20 \mathrm{mg} / \mathrm{ml}$ high glucose condition. Amylin markedly inhibited the stimulatory activity of glybenclamide (Fig. 5B, $\mathrm{P}<0.01$ ); however, no effect was observed on the stimulatory activity of fucoidan.

Involvement of the cAMP signaling pathway. Following incubation of the RIN-5F cells in RPMI 1640 medium supplemented with penicillin, streptomycin and $10 \% \mathrm{FBS}$ at $37^{\circ} \mathrm{C}$ in an atmosphere containing $5 \% \mathrm{CO}_{2}$ for $24 \mathrm{~h}$, the cells were treated with various doses of fucoidan $\left(0,10,1 \times 10^{2}, 1 \times 10^{3}\right.$, 
A

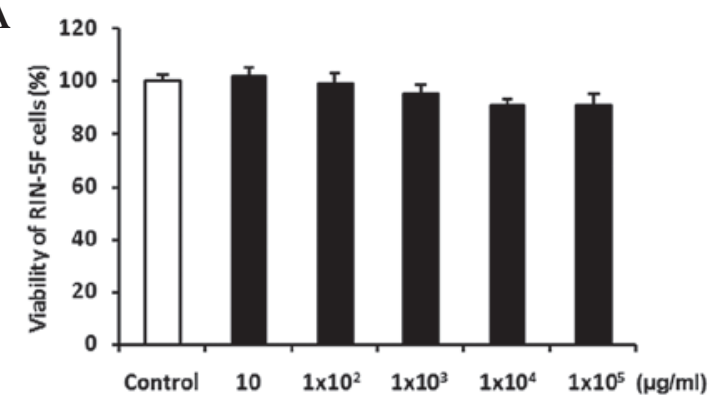

B
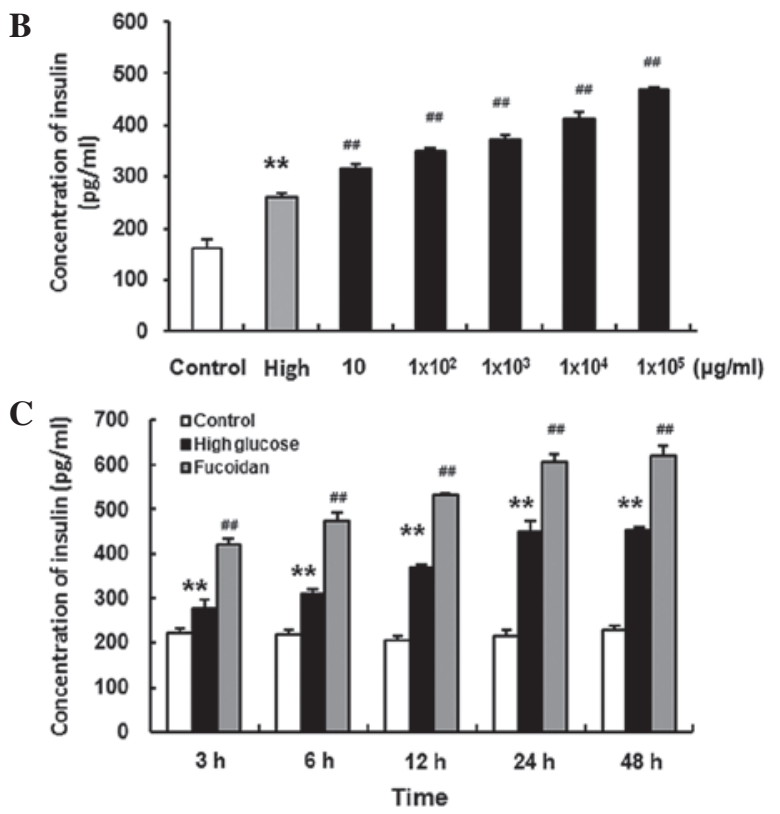

Figure 4. (A) RIN-5F rat insulin-secreting cells were treated with various concentrations of fucoidan $\left(0,10,1 \times 10^{2}, 1 \times 10^{3}, 1 \times 10^{4}, 1 \times 10^{5} \mu \mathrm{g} / \mathrm{ml}\right)$. Fucoidan exhibited no cytotoxicity towards the RIN-5F cells. (B and C) RIN-5F cells were treated with various doses of fucoidan $\left(0,10,1 \times 10^{2}, 1 \times 10^{3}, 1 \times 10^{4}\right.$ and $\left.1 \times 10^{5} \mu \mathrm{g} / \mathrm{ml}\right)$ for $3 \mathrm{~h}$; and with $1 \times 10^{4} \mu \mathrm{g} / \mathrm{ml}$ fucoidan for various time periods $(3,6,12,24$ and $48 \mathrm{~h}$,) in a $20 \mathrm{mg} / \mathrm{ml}$ high glucose condition. Treatment with fucoidan increased the insulin secretion of RIN-5F cells in a dose-and time-dependent manner. The concentrations of insulin were normalized with the numbers of cells. Data are expressed as the mean \pm standard deviation $(n=3) .{ }^{* *} \mathrm{P}<0.01$, high glucose, vs. control; ${ }^{\# \#} \mathrm{P}<0.01$, high glucose + fucoidan, vs. high glucose.

$1 \times 10^{4}$ and $1 \times 10^{5} \mu \mathrm{g} / \mathrm{ml}$ ) for $3 \mathrm{~h}$ (Fig. 6A); and with $1 \times 10^{4} \mu \mathrm{g} / \mathrm{ml}$ fucoidan for 3, 6, 12, 24 and $48 \mathrm{~h}$ (Fig. 6B) in a $20 \mathrm{mg} / \mathrm{ml}$ high glucose condition. The concentration of cAMP was significantly increased in the fucoidan-treated RIN-5F cells, and this occurred in a dose-and time-dependent manner $(\mathrm{P}<0.01)$. Treatment with the phosphodiesterase inhibitor, $2 \times 10^{-5} \mathrm{M}$ 4-(3-butoxy-4-methoxybenzyl)-2-imidazolidinone, which decreases the degradation of cAMP, significantly increased the level of fucoidan-induced insulin secretion. Conversely, treatment with adenylyl cyclase inhibitor, $5 \times 10^{-5} \mathrm{M}$ MDL-12330A hydrochloride, which decreases cAMP generation, significantly decreased the level of fucoidan-induced insulin secretion $(\mathrm{P}<0.01$; Fig. $7 \mathrm{~A}$ and $\mathrm{B})$.

\section{Discussion}

The present study is the first, to the best of our knowledge, to demonstrate in vivo and in vitro, that fucoidan, an extract of the seaweed Fucus vesiculosus, reduced hyperglycemia and prevented or reduced the development of spontaneous diabetes. Diabetes is a global disease (1), the incidence and prevalence of which have reached epidemic proportions (19). The number of individuals affected by diabetes mellitus is estimated to be $>200,000,000$. The majority of patients with diabetes have NIDDM (2), and the number of patients with NIDDM is expected to double by 2030 (20). The insulin stimulatory activities of SUs have been reported to decrease with time, due to the gradual destruction of pancreatic $\beta$ cells, and SUs are prescribed with a number of restrictions due to their associated side-effects, including hypoglycemia (3).

Interest regarding the biological activities of compounds obtained from marine organisms has intensified in previous years (4). Compounds derived from various marine organisms have been investigated, a number of which have been developed into commercially available drugs (3). Fucoidan is a compound, which possesses anti-oxidant, anticancer, and anti-inflammatory activities, and has been widely investigated (7). Fucoidan can suppress various inflammatory cytokines, including interleukin-1 $\beta$, tumor necrosis factor- $\alpha$, interferon- $\gamma$ and cyclooxygenase-2 (21). In addition, fucoidan has been reported to be important role in cancer and inflammation (8), and to be associated with insulin resistance (9). Therefore, the present study aimed to investigate the effects of fucoidan on insulin stimulation and pancreatic protection.

GK rats are non-obese rats, originally derived by repeated inbreeding of glucose-intolerant Wistar rats (15), which exhibit spontaneous and moderate NIDDM. Between 3 and 4 weeks of age, GK rats develop mild hyperglycemia and hyperinsulinemia. Therefore, GK rats were selected for use in the present study, and Wistar rats were used as a control. In the in vivo investigation, the body weights and levels of serum insulin decreased, and blood glucose levels significantly increased in the GK rats, compared with the control Wistar rats. Although fucoidan did not alter body weight, the observed increase in blood glucose levels were reduced and the decreased serum insulin levels were recovered in the GK rats following oral administration of fucoidan for 13 weeks. Histopathological analysis also demonstrated that islet atrophy, fibrosis of pancreatic ducts and blood vessels, and macrophages containing brown coarsely granular material were observed in the pancreata of GK rats, compared with the control Wistar rats. Treatment with fucoidan markedly reduced the histopathological changes in the pancreatic tissues of the GK rats. In vitro, dose- and time-dependent effects of fucoidan on insulin concentration were determined in RIN-5F cells cultured in high glucose conditions. Fucoidan was not observed to be cytotoxic towards RIN-5F cells, and significantly stimulated insulin secretion in a dose-and time-dependent manner.

Under physiological conditions, the insulin secretory response to glucose is augmented by numerous factors, which act through various mechanisms (11). It is well-known that insulin secretion from pancreatic $\beta$ cells is stimulated by SUs. SUs bind to SU receptors, resulting in the closure of ATP sensitive $\mathrm{K}^{+}$channels in the pancreatic $\beta$ cell plasma membrane, which leads to membrane depolarization, rapid $\mathrm{Ca}^{2+}$ influx and insulin secretion (22). SUs act by direct interaction with the secretory machinery. In addition, physiological insulin secretion is regulated by numerous intrinsic factors (23), including free fatty acids, amino acids and newly identified hormones, including glucagon-like polypeptide-1 (24) and pituitary adenylate cyclase activating polypeptide (25). Intracellular signal transduction, 
A

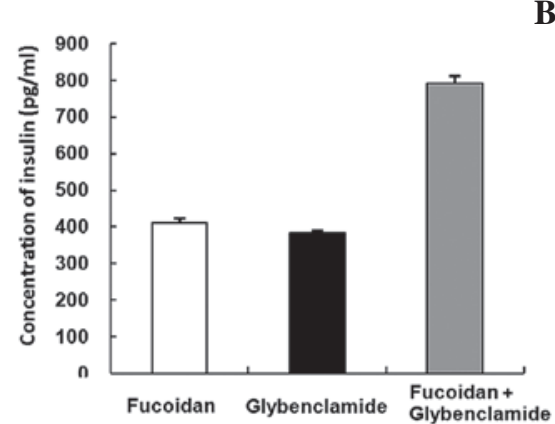

B

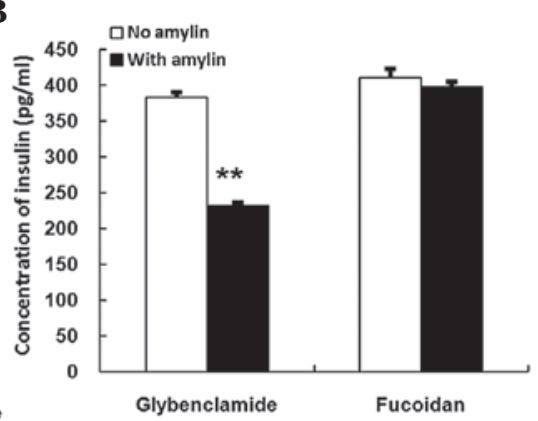

Figure 5. (A) Stimulatory activities of fucoidan and glybenclamide. RIN-5F rat insulin-secreting cells were treated with $1 \times 10^{4} \mu \mathrm{g} / \mathrm{ml}$ fucoidan and $1 \times 10^{2} \mu \mathrm{M}$ glybenclamide, either alone or in combination with $20 \mathrm{mg} / \mathrm{ml}$ high glucose for $3 \mathrm{~h}$. The results suggested an additive effect of fucoidan and glybenclamide. (B) Amylin did not exhibit an inhibitory effect on fucoidan. RIN-5F cells were treated with $200 \mu \mathrm{M}$ amylin and $1 \times 10^{4} \mathrm{~g} / \mathrm{ml}$ fucoidan or $1 \times 10^{2} \mu \mathrm{M}$ glybenclamide in a $20 \mathrm{mg} / \mathrm{ml}$ high glucose condition. Amylin markedly inhibited the stimulatory activity of glybenclamide, but had no effect on the stimulatory activity of fucoidan. Data are expressed as the mean \pm standard deviation $(n=3)$. ** $\mathrm{P}<0.01$, amylin, vs. no amylin.
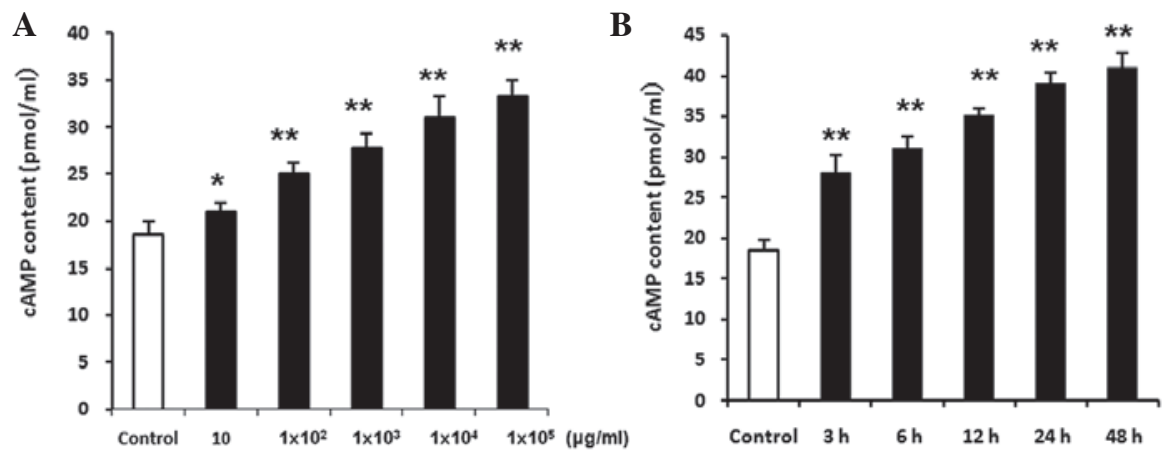

C

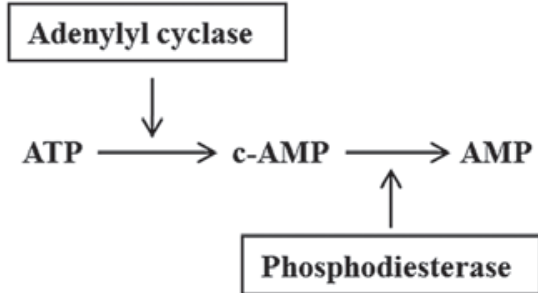

Figure 6. RIN-5F rat insulin-secreting cells were treated with (A) various doses of fucoidan $\left(0,10,1 \times 10^{2}, 1 \times 10^{3}, 1 \times 10^{4}\right.$ and $\left.1 \times 10^{5} \mu \mathrm{g} / \mathrm{ml}\right)$ for $3 \mathrm{~h}$ and with (B) $1 \times 10^{4} \mu \mathrm{g} / \mathrm{ml}$ fucoidan for various time periods $(3,6,12,24$ and $48 \mathrm{~h})$ in a $20 \mathrm{mg} / \mathrm{ml}$ high glucose condition. The concentration of cAMP was significantly increased in the fucoidan-treated RIN-5F cells, in a dose-and time-dependent manner. (C) Generation and degradation of cAMP. Phosphodiesterase inhibitor decreased the degradation of cAMP, whereas adenylyl cyclase inhibitor decreased the generation of cAMP. The cAMP contents were normalized with the numbers of cell. Data are expressed as the mean \pm standard deviation $(n=3)$. ${ }^{*} \mathrm{P}<0.05$ and ${ }^{* *} \mathrm{P}<0.01$, vs. control.. ATP, adenosine triphosphate; cAMP, cyclic adenosine monophosphate.

A

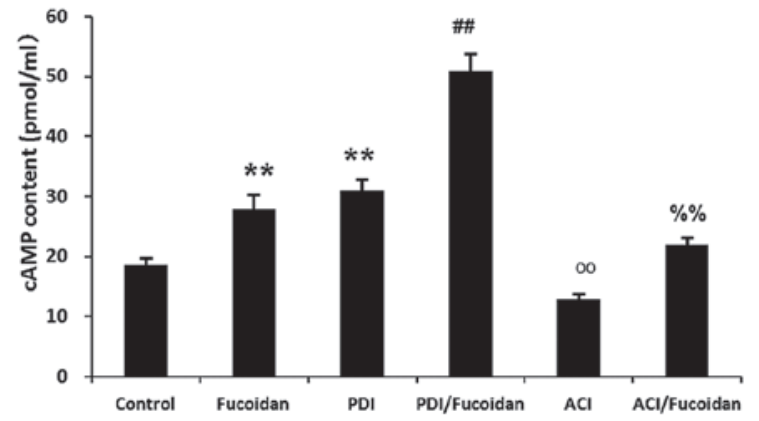

B

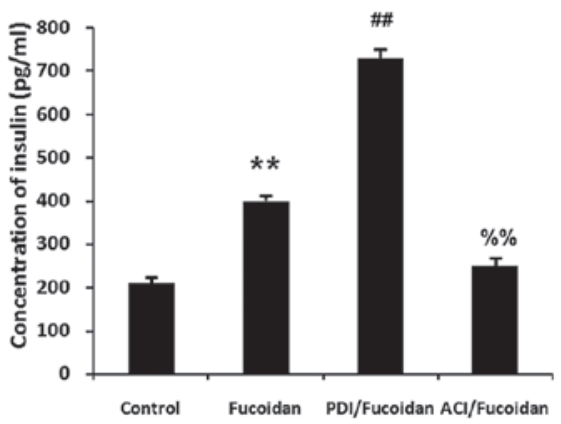

Figure 7. RIN-5F rat insulin-secreting cells were treated with $1 \times 10^{4} \mu \mathrm{g} / \mathrm{ml}$ fucoidan, $2 \times 10^{-5} \mathrm{M}$ PDI, PDI + fucoidan, ACI or ACI + fucoidan, in a $20 \mathrm{mg} / \mathrm{ml}$ high glucose condition. (A) Fucoidan and PDI increased the concentration of cAMP, whereas ACI significantly decreased the effects of fucoidan. (B) Treatment with a PDI significantly increased the fucoidan-induced insulin secretion, whereas treatment with an ACI significantly decreased the fucoidan-induced insulin secretion. Data are expressed as the mean \pm standard deviation $(\mathrm{n}=3) .{ }^{* *} \mathrm{P}<0.01$, fucoidan or PDI, vs. control; ${ }^{\# \#} \mathrm{P}<0.01$, $\mathrm{PDI}+$ fucoidan, vs. fucoidan; ${ }^{\circ} \mathrm{P}<0.01, \mathrm{ACI}$, vs. control; ${ }^{\% \%} \mathrm{P}<0.01, \mathrm{ACI}+$ fucoidan, vs. fucoidan. PDI, phosphodiesterase inhibitor; ACI, adenylyl cyclase inhibitor; cAMP, cyclic adenosine monophosphate.

including $\mathrm{K}_{\mathrm{ATP}}$ channel-dependent and -independent mechanisms, the ATP-gated $\mathrm{P} 2 \mathrm{X} 3$ receptor mechanism (26), and the extracellular calcium-sensing receptor mechanism, which includes the mitogen-activated protein kinase cascade for insulin secretion, have also been elucidated $(27,28)$. In the present study, glybenclamide was used as a positive control, and the results suggested an additive effect of fucoidan and glybenclamide. Amylin is an inhibitor of glybenclamide, which was shown to markedly inhibit the stimulatory activity of glybenclamide; however, it did not inhibit the stimulatory activity of fucoidan, 
suggesting that the effects of fucoidan on insulin secretion may be associated with a different mechanism, which varies from the rapid $\mathrm{Ca}^{2+}$ influx caused by glybenclamide.

cAMP is well documented to be an important amplifier of insulin release (12). cAMP directly inhibits $\mathrm{K}_{\mathrm{ATP}}$ channels and promotes depolarization of the plasma membrane. In addition, cAMP increases cytosolic $\mathrm{Ca}^{2+}$ levels via opening of L-type voltage-sensitive $\mathrm{Ca}^{2+}$ channels in the plasma membrane, and promotion of $\mathrm{Ca}^{2+}$-induced $\mathrm{Ca}^{2+}$ release from intracellular stores (13). Elevation in cAMP levels has also been observed to stimulate insulin exocytosis, independent of changes in intracellular $\mathrm{Ca}^{2+}$ concentration (29). In order to better understand the mechanisms underlying the stimulatory activity of fucoidan, the concentration of cAMP was measured in RIN-5F cells in the present study. The concentration of cAMP was significantly increased in the fucoidan-treated RIN-5F cells, in a dose-and time-dependent manner. The generation and degradation of cAMP is shown in Fig. 4C, where phosphodiesterase inhibition decreased the degradation of cAMP and adenylyl cyclase inhibition decreased the generation of cAMP. Treatment with the phosphodiesterase inhibitor significantly increased fucoidan-induced insulin secretion, whereas treatment with the adenylyl cyclase inhibitor significantly decreased fucoidan-induced insulin secretion. These results suggested that the cAMP signaling pathway may be important in the process. However, the role of fucoidan in the regulation of insulin secretion via the cAMP signaling pathway under physiological conditions remains to be fully elucidated. The complex process and mechanism requires further investigation.

The present study is the first, to the best of our knowledge, to determine the effects of fucoidan on insulin stimulation and pancreatic protection via the CAMP signaling pathway in vivo and in vitro. These results indicated that fucoidan may prevent or reduce the development of spontaneous diabetes, and may be considered a novel therapeutic strategy for its treatment.

\section{References}

1. Fang Y, Tian X, Bai S, Fan J, Hou W, Tong H and Li D: Autologous transplantation of adipose-derived mesenchymal stem cells ameliorates streptozotocin-induced diabetic nephropathy in rats by inhibiting oxidative stress, pro-inflammatory cytokines and the p38 MAPK signaling pathway. Int J Mol Med 30: 85-92, 2012.

2. Tsur A, Harman-Bohem I, Buchs AE, Raz I and Wainstein J: The guidelines for the diagnosis prevention and treatment of type 2 diabetes mellitus - 2005. Harefuah 145: 583-586, 630, 2006 (In Hebrew).

3. Genuth S: Management of the adult onset diabetic with sulfonylurea drug failure. Endocrinol Metab Clin North Am 21: 351-370, 1992.

4. Onofrejová L, Vasícková J, Klejdus B, Stratil P, Misurcová L, Krácmar S, Kopecký J and Vacek J: Bioactive phenols in algae: The application of pressurized-liquid and solid-phase extraction techniques. J Pharm Biomed Anal 51: 464-470, 2010.

5. Li X, Zhao H, Wang Q, Liang $\mathrm{H}$ and Jiang X: Fucoidan protects ARPE-19 cells from oxidative stress via normalization of reactive oxygen species generation through the $\mathrm{Ca}^{2+}$-dependent ERK signaling pathway. Mol Med Rep 11: 3746-3752, 2015.

6. Zhang P, Bi C, Schmitt SM, Li X, Fan Y, Zhang N and Dou QP Metal-based 2,3-indolinedione derivatives as proteasome inhibitors and inducers of apoptosis in human cancer cells. Int J Mol Med 34: 870-879, 2014.

7. Myers SP, O'Connor J, Fitton JH, Brooks L, Rolfe M, Connellan P, Wohlmuth H, Cheras PA and Morris C: A combined Phase I and II open-label study on the immunomodulatory effects of seaweed extract nutrient complex. Biologics 5: 45-60, 2011.
8. Li C, Gao Y, Xing Y, Zhu H, Shen J and Tian J: Fucoidan, a sulfated polysaccharide from brown algae, against myocardial ischemia-reperfusion injury in rats via regulating the inflammation response. Food Chem Toxicol 49: 2090-2095, 2011.

9. Hernández-Corona DM, Martínez-Abundis E and González-Ortiz M: Effect of fucoidan administration on insulin secretion and insulin resistance in overweight or obese adults. J Med Food 17: 830-832, 2014.

10. Eliza J, Daisy P, Ignacimuthu S and Duraipandiyan V: Antidiabetic and antilipidemic effect of eremanthin from Costus speciosus (Koen.)Sm., in STZ-induced diabetic rats. Chem Biol Interact 182: 67-72, 2009.

11. Henquin JC: The dual control of insulin secretion by glucose involves triggering and amplifying pathways in $\beta$-cells. Diabetes Res Clin Pract 93 (Suppl 1): S27-S31, 2011.

12. Damdindorj B, Dezaki K, Kurashina T, Sone H, Rita R, Kakei M and Yada T: Exogenous and endogenous ghrelin counteracts GLP-1 action to stimulate cAMP signaling and insulin secretion in islet $\beta$-cells. FEBS Lett 586: 2555-2562, 2012.

13. Furman B, Ong WK and Pyne NJ: Cyclic AMP signaling in pancreatic islets. Adv Exp Med Biol 654: 281-304, 2010.

14. Meenakshi S, Umayaparvathi S, Saravanan R, Manivasagam T and Balasubramanian T: Hepatoprotective effect of fucoidan isolated from the seaweed Turbinaria decurrens in ethanol intoxicated rats. Int J Biol Macromol 67: 367-372, 2014.

15. Kim CS, Sohn EJ, Kim YS, Jung DH, Jang DS, Lee YM, Kim DH and Kim JS: Effects of KIOM-79 on hyperglycemia and diabetic nephropathy in type 2 diabetic Goto-Kakizaki rats. J Ethnopharmacol 111: 240-247, 2007.

16. Lan T, Shen X, Liu P, Liu W, Xu S, Xie X, Jiang Q, Li W and Huang H: Berberine ameliorates renal injury in diabetic C57BL/6 mice: Involvement of suppression of SphK-S1P signaling pathway. Arch Biochem Biophys 502: 112-120, 2010.

17. Zhang D, Fujii I, Lin C, Ito K, Guan H, Zhao J, Shinohara M and Matsukura M: The stimulatory activities of polysaccharide compounds derived from algae extracts on insulin secretion in vitro. Biol Pharm Bull 31: 921-924, 2008.

18. Xie P, Nishiura H, Semba U, Chen J, Zhao R, Kuniyasu A and Yamamoto $\mathrm{T}$ : Inhibitory effects of $\mathrm{C} 4 \mathrm{a}$ on chemoattractant and secretagogue functions of the other anaphylatoxins via Gi protein-adenylyl cyclase inhibition pathway in mast cells. Int Immunopharmacol 12: 158-168, 2012.

19. Hall GM and Ruggier R: Diabetes mellitus and anaesthesia. Curr Opin Anaesthesiol 12: 343-347, 1999.

20. Parker JC: Troglitazone: The discovery and development of a novel therapy for the treatment of Type 2 diabetes mellitus. Adv Drug Deliv Rev 54: 1173-1197, 2002.

21. Fukahori S, Yano H, Akiba J, Ogasawara S, Momosaki S, SanadaS, Kuratomi K, Ishizaki Y, Moriya F, Yagi M and Kojiro M: Fucoidan, a major component of brown seaweed, prohibits the growth of human cancer cell lines in vitro. Mol Med Rep 1: 537-542, 2008.

22. Samarasinghe $S$ and Vokes T: Diabetes insipidus. Expert Rev Anticancer Ther 6 (Suppl 9): S63-S74, 2006.

23. Jacques-SilvaMC,Correa-Medina M,CabreraO,Rodriguez-DiazR, Makeeva N, Fachado A, Diez J, Berman DM, Kenyon NS, Ricordi C, et al: ATP-gated P2X3 receptors constitute a positive autocrine signal for insulin release in the human pancreatic beta cell. Proc Natl Acad Sci USA 107: 6465-6470, 2010.

24. Hölscher C: The incretin hormones glucagonlike peptide 1 and glucose-dependent insulinotropic polypeptide are neuroprotective in mouse models of Alzheimer's disease. Alzheimers Dement 10 (1 Suppl): S47-S54, 2014.

25. Ma Y, Luo T, Xu W, Ye Z and Hong A: A new recombinant pituitary adenylate cyclase-activating peptide-derived peptide efficiently promotes glucose uptake and glucose-dependent insulin secretion. Acta Biochim Biophys Sin (Shanghai) 44: 948-956, 2012.

26. Widenmaier SB, Ao Z, Kim SJ, Warnock G and McIntosh $\mathrm{CH}$ : Suppression of p38 MAPK and JNK via Akt-mediated inhibition of apoptosis signal-regulating kinase 1 constitutes a core component of the beta-cell pro-survival effects of glucose-dependent insulinotropic polypeptide. J Biol Chem 284: 30372-30382, 2009.

27. Chalon S, Vancassel S, Zimmer L, Guilloteau D and Durand G: Polyunsaturated fatty acids and cerebral function: Focus on monoaminergic neurotransmission. Lipids 36: 937-944, 2001.

28. Fedor D and Kelley DS: Prevention of insulin resistance by n-3 polyunsaturated fatty acids. Curr Opin Clin Nutr Metab Care 12: 138-146, 2009.

29. Tengholm A: Cyclic AMP dynamics in the pancreatic $\beta$-cell. Ups J Med Sci 117: 355-369, 2012. 